\title{
Determination of a Particle Size Distribution Criterion for Predicting Dense Phase Pneumatic Conveying Behaviour of Granular and Powder Materials
}

\author{
Tong Deng* and Michael S.A. Bradley \\ The Wolfson Centre for Bulk Solids Handling Technology, Faculty of Engineering \& Science, University \\ of Greenwich, Central Avenue, Chatham, Kent ME4 4TB, UK \\ * Corresponding author: Tel.: ++44 (0)20 8331 9951; Email: t.deng@greenwich.ac.uk
}

Keywords: Particle Size, Size Distribution Influence, Pneumatic Conveying Characteristics, Powders

\begin{abstract}
The purpose of this study was to evaluate the effect of particle size distribution on the modes of flow that particulate materials will support in a pneumatic conveying pipeline. It has long been known that some materials can be conveyed in dense phase flow, i.e. a condition wherein the superficial gas velocity is below the saltation value, whereas some materials will block the pipeline under such conditions. It has also been known for a long time that there are two distinct forms of dense phase flow, generally linked to whether the material is fine (such as cement powder), or coarse (such as pellets), but until now there has been no successful method to assess the conveyability of a material based on size distribution alone. Six materials with different size grades were conveyed in a $25 \mathrm{~mm}$ bore pipeline, at a range of pressures up to 3 bar and gas velocities from zero to $12 \mathrm{~m} / \mathrm{s}$. The results showed that materials below a certain size would support a fluid-like dense phase mode of flow, whereas to support a low-velocity slug flow the key was to have a very narrow size distribution. Materials that satisfied neither of these criteria would not support flow at gas velocities below the saltation value. Clear trends for how throughput changes in the transition from lean to dense phase, are also demonstrated, which have major implications for pipeline sizing. A quantitative criterion for deciding on the likely conveyability of a material, based on size distribution alone, is proposed.
\end{abstract}

Keywords: Pneumatic Conveying Characteristics; Particulate Materials; Size Influence; Modes of Flow;

\section{Introduction}

Pneumatic conveying of particulate materials has been popular for many decades for industrial applications that can benefit from its inherent advantages of enclosed conveying (offering complete control over contamination of the environment from the material, and contamination of the material from the environment), and also its flexibility of routing (ability to change direction without a transfer station) [1]. However in practice, successful running of a pneumatic conveyor depends completely upon the characteristics of the material conveyed, which is not only different between different materials, but may also vary from one batch to another of (nominally) the same material. To design a reliable pneumatic conveying line, understanding of the "conveying characteristics" of the material in the line is critical; these "conveying characteristics" comprise the relationship between the air and solids flow rates and the pressure drop, and also the "minimum transport velocity" (strictly the lowest superficial air velocity required for reliable transport).

In terms of the minimum transport velocity, it has been known qualitatively for some decades that this depends on the particle characteristics of the material, in particular the particle size distribution and proportion of fine content in the material [2]. The minimum transport velocity is the single most critical parameter in conveyor design, because it determines the achievable pattern of flow in the pipelines (specifically, "is dense phase conveying possible with this material?" [3]) and the pressure drop, as well as the air volume required, so it affects fundamental design choices such as the feeder and air mover types to be used. Therefore, understanding the influence of particulate size on 
pneumatic conveying characteristics is important for design of a reliable pneumatic conveyor for different particulates, at least for a "first cut assessment" of a plant design, or of a new material for an existing plant, prior to undertaking conveying trials to obtain detailed information for design.

Generally for some materials, provided the system can provide sufficient pressure to overcome the increased pressure drop of the flow, this can facilitate a class of flow known as "dense phase" in which a highly heterogeneous flow pattern is developed, consisting of "slugs" or "plugs" of material moving along the pipe. However with many materials, the onset of such slugging simply leads to a pipeline blockage, which is not cleared by further increases in pressure, but can only be motivated by special measures such as injecting air through the wall of the pipe at a location along the length of the slug.

Due to increasing industry interest in pneumatic conveying, some research was carried out in the 1980 s to try to understand what features of the particles control the ability of a material to support different type of flows or not as the case may be, especially for dense phase pneumatic conveying [3]. In 1973, Geldart [4] published what has become probably the single best known piece of work related to powder/air interaction, a diagram classifying materials according to their behaviour in fluid beds, based on median particle size and density, as shown in Figure 1.

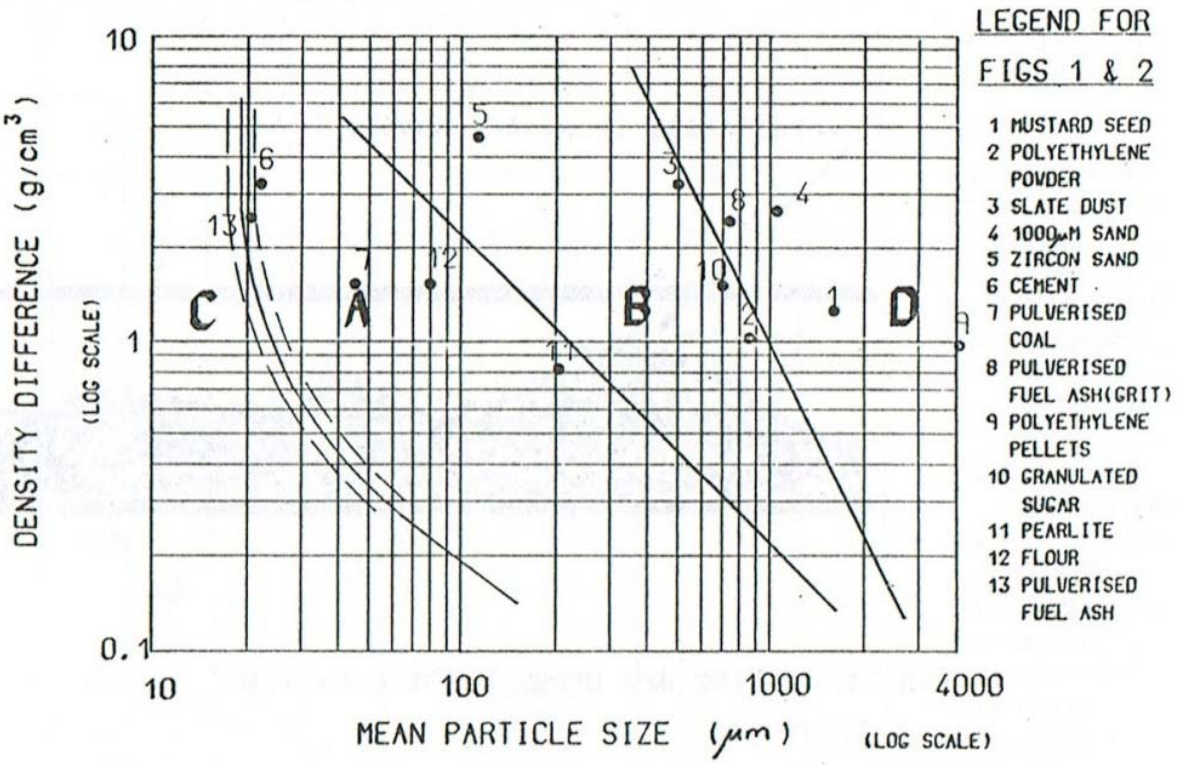

Figure 1: Geldart diagram for fluidisation, with materials tested by Mainwaring and Reed added (from Ref. 6, with permission of the author)

It would seem quite natural to suspect that the ability of a material to convey in dense phase could be linked to its ability to fluidise, so Dixon [5] proposed a "slugging diagram" based on the Geldart classification, in an attempt to predict the likely dense phase conveying behaviour of a material from the median size and density of its particles (see Figure 2). Dixon undertook tests with only a limited range of materials to support his thesis that materials in groups $D$ and $A$ are conveyable in dense phase, and others not, with the delineation between groups dependent on air pressure. However, further examination of Dixon's slugging diagram by other contemporary researchers found it to be useless. Mainwaring and Reed [6] tested a wide range of different materials and found that the dense phase conveying capabilities of materials he tested in a $50 \mathrm{~mm}$ pipeline were not at all as predicted by Dixon's 
slugging diagram; in each of Dixon's groups, he found both materials that would convey in dense phase, and materials that would not.

Hitt and Mainwaring $[7,8]$ both investigated modes of dense phase flow using glass pipes and movie film, and found two distinctly different modes of dense phase flow; for granular materials such as pellets, granulated sugar and closely-graded coarse sand, they found a form of flow with slow-moving full-bore slugs crawling through the pipeline, with clear air between the slugs and a bed of stationary particles on the floor of the pipe in horizontal sections. Powder materials, however, flowed in a mode more akin to a mix of gas and liquid in a pipe, tending to move faster and more irregularly and without the same clear distinction between clear air and dense slugs. These modes of flow have since become popularly known as "low velocity slug flow" and "fluidised dense phase flow" respectively.

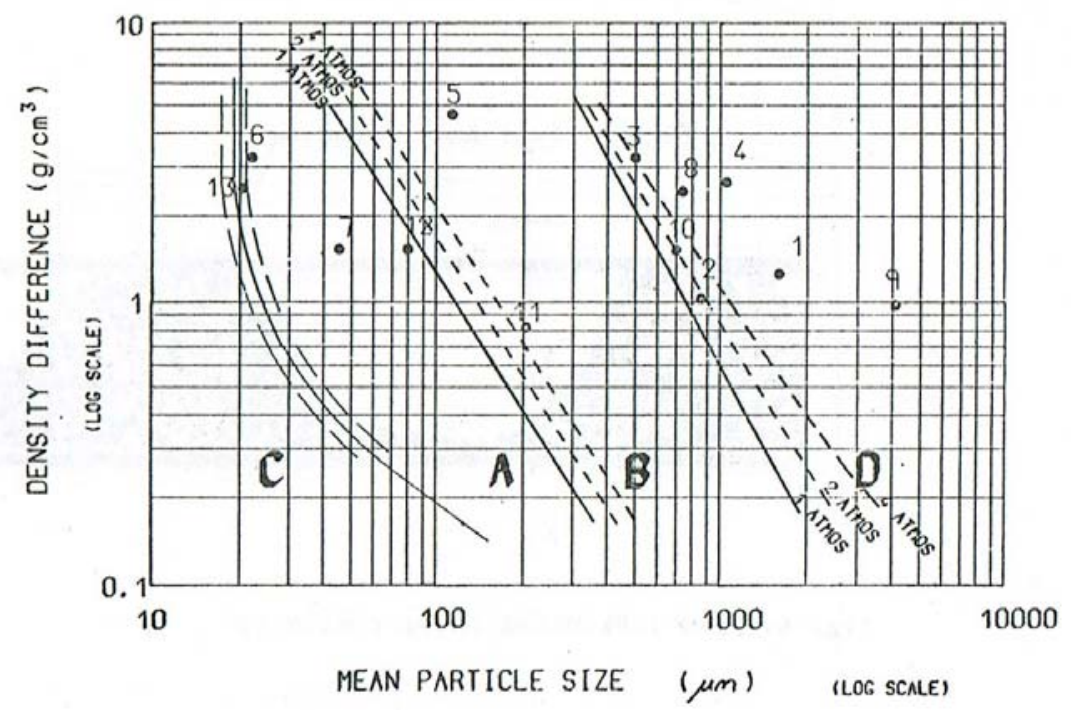

Figure 2: Dixon "slugging diagram" for pneumatic conveying, with materials tested by Mainwaring and Reed in $53 \mathrm{~mm}$ pipeline added (see legend in Fig. 1) (from Ref. 6, with permission of the author)

Jones [9] undertook an investigation of a number of materials that had differing particle sizes, and looked at whether or not they would convey in dense phase. He tried with no success to correlate the dense phase conveyability against particle size and other properties, but eventually came up with the idea that the permeability of the material might be a useful quantity to correlate; he tried a de-aeration test which showed some promise, and refined it into a "vibrated de-aeration test" in which a sample of the material is fluidised in a fluidisation column, then the air turned off as vibration was turned on, and recorded the decay in air pressure at the bottom of the column. The vibration was found to be essential to obtain a good correlation; this was probably due to its ability to break the wall friction between the powder and the wall of the fluidising column, to allow de-aeration to proceed without this factor influencing it. Jones found that materials that de-aerated extremely quickly would convey well in dense phase, in low velocity slug flow, whereas materials that de-aerated slowly would also flow well in dense phase but in a fluidised dense phase form. Materials in the middle would not convey in dense phase; if they slugged, they blocked the pipeline.

The combined output of Hitt, Mainwaring and Jones $[8,9]$ was seminal in that it showed that a high degree of permeability is required in the material to support low velocity slug flow, whereas a high level of air-retentiveness is required to support fluidised dense phase flow. Any material that does not display either one or other of these two properties, cannot be conveyed in dense phase in a "normal" pipeline system (i.e. a system without air injectors along the pipe run). 
Whilst their work did not directly indicate the particle characteristics required to support the different modes of dense phase flow, the above considerations do give a clue to the effect of size distributions;

- To have a high level of permeability, a material has to have an "open" structure, which requires an absence of fine particles filling the gaps between the bigger ones, i.e. a narrow size distribution. This facilitates low velocity slug flow, in which it appears that the critical matter is the ability of the air to percolate through a full-bore slug producing a pressure drop and hence a force which is distributed through the length of the slug; this means that the slug is effectively pulled along from the inside rather than pushed by the air pressure behind it, which would cause it to "lock" in the pipe due to the Janssen [10] effect (high and localised axial pressure on the bulk of particles gives rise to a lateral pressure against the pipe wall, invoking wall friction which prevents sliding of the slug along the pipe).

- To retain air well, a powder requires a great complexity of interstices, i.e. a dominant proportion of fine particles. Once the material has been mixed with air, it retains the air for a period, maintaining a liquid-like behaviour, so as long as the flow is moving, the air and particles remain in a fluid-like form due to continuous agitation and mixing of air and powder. In a liquid-like form, the material is unable to support a shear stress whilst at rest, instead exhibiting a viscosity (various workers e.g. [11] have characterised fluidised powders and shown their behaviour to be very like a normal liquid). With sufficient pressure available, the slugs of fluidised powder will flow like slugs of water or oil in a gas-liquid flow.

- If the particles are not sufficiently fine, they will not maintain a fluid-like condition for any significant period, so the fluidised behaviour is lost as the material flows through the pipeline. It de-aerates, and in this condition it can support a shear stress at the wall whilst at rest. However if at the same time the size distribution is not sufficiently narrow, little air can percolate through the slug, so all the pressure drop is applied at the trailing end of the slug, in which condition the Janssen effect causes the slug to lock in the pipeline and further increases in air pressure simply cause the plug to become more compact and harder to move.

A number of papers since have been published by a variety of authors offering some refinement of this approach and some analytical models [12-15], but any meaningful approach has continued to require the testing of a sample of material for permeability [16]. Until now there has never been any work to establish a quantitative set of criteria for the size distribution required to support dense phase flow. This can be a limitation for a designer, because often it is not convenient to obtain a sample at an early stage of quoting a conveyor design; sometimes the material is not easy to obtain because the project is in another country, the material has not yet been made in sufficient quantity, or obtaining it would put a long delay into the design process. Also, the cost of obtaining and testing the sample can be hard to justify if the company is one of several quoting for the contract so has only a slim chance of winning it. If a sample of several litres has to be obtained in order to undertake a permeability test, it can be argued that there is not much more cost and time involved in getting a larger sample (a barrel or two of material) and undertaking pipeline tests, which not only give much more certainty regarding the possibility of dense phase conveying but also give reliable data for pressure drop and pipe size calculations. The real advantage to a designer, would be to have a method to allow an assessment of likely dense phase conveying ability of a material from a knowledge of easily obtainable particle properties such as size distribution, so that testing a sample could be avoided at least as a first-stage assessment. It is critical to understand that this would NOT eliminate the need for pipeline tests to obtain pressure drop data, if the contract is won. 


\section{$2 \quad 2.1$ Test apparatus}

3 A dense phase pneumatic conveying test facility was used at the Wolfson Centre, comprising a bottom 4 discharge blow tank, in conjunction with a pipeline of one inch nominal bore $(25 \mathrm{~mm})$, schedule 80 carbon steel, instrumented to gather data on pressures at blow tank, pipe inlet, receiving hopper and venting point, and flow rates of solids and conveying gas. The layout of the test rig and the pipe route and blow tank are shown in Figure 3(a). It shows the bottom discharge blow tank with a ball valve to control solid flow rate. The gas supply routes are not shown in the figure, but comprised a pipeline gas supply via a flow controller to the start of the pipeline (just upstream of the delivery of the solids) and a blow tank gas supply via a pressure regulator and variable-area flow meter to feed air to the tank (near the base) to maintain the tank pressure up to 6 bar gauge.

The total conveying pipe length is about 30 metres including a rubber hose of about 12 metres at the end of conveying line (see Figure $3(b)$ ). The vertical section of metal pipe is about 5 meters and the rest is horizontal. The total number of bends is 6 including 4 metal bends and 2 bends in the rubber hose. The particular layout and pipe size was used because it represented a typical installation of pipelines used to inject particulate materials into ladles of molten steel for alloying, the business of the sponsors. However, the incorporation of the rubber hose section offered a particularly useful opportunity to observe whether slugging was occurring (indicated by movement of the hose).

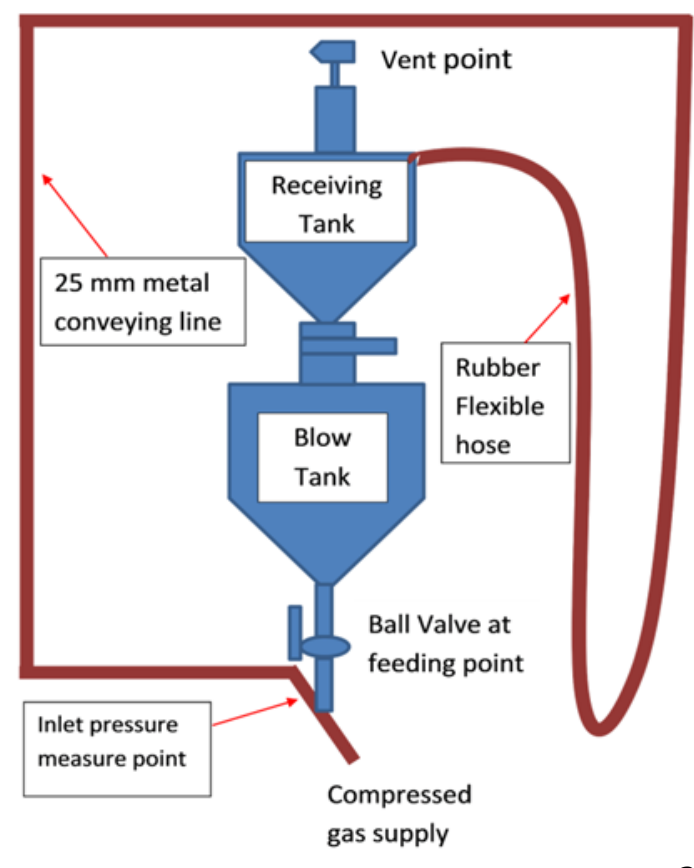

a)

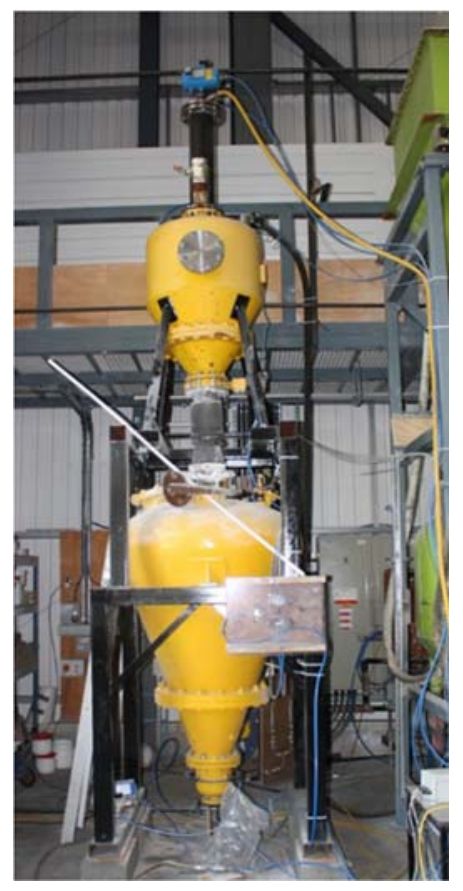

Figure 3: a) Schematic of the pneumatic conveyıng pipeline, and b) discharge \& receive tan.

b)

\subsection{Test procedure and conditions}

The pneumatic conveying tests were carried out for the test materials over as wide a range of operating conditions as could be achieved, so full conveying characteristics of the materials could be obtained. For conveying tests, the test material was pre-loaded into the blow tank. The blow tank was pressurised before the conveying started. Then the ball valve was opened to a predetermined position for solids flow rate control; various settings were used in subsequent test runs to achieve a range of solids flow rates for the same gas flow rate. While the conveying was under way, pressures in blow 
tank, pipe inlet, receiving vessel and venting point were recorded using electronic pressure transducers (Druck's PDCR 840) and a data logger (NI Signal Express ${ }^{\circledR}$ ) (see Figure 3(a)). Flow rates of gas to blow tank and injection gas were recorded. The accumulating weight of conveyed material in the receiving vessel was also recorded.

For each individual test material, high rates of conveying gas flow were used initially, and after testing with a range of solids flow rates the gas flow was reduced and the tests repeated. Eventually, with further reductions in gas flow, pipeline blockage occurred due to insufficient gas velocity to transport the material. The lowest gas velocity that was used successfully to convey the material was identified as the minimum conveying gas velocity. It is known that this critical gas velocity is always at the beginning of the pipeline, because gas velocity increases along the line while the gas is expanded. The minimum conveying velocity is a key characteristic for pneumatic conveying and also a design factor that must be taken into account.

In the tests of each material, 10 to 15 conveying test conditions were attempted to cover gas flow rates, solid flow feeding rates and conveying velocities of materials, which can be found in corresponding diagrams of the test results. Typically 4 or 5 different gas flow rates between about 10 $\mathrm{m}^{3} / \mathrm{h}$ and $70 \mathrm{~m}^{3} / \mathrm{h}$ were used so different inlet gas velocities could be achieved. The total gas pressure at inlet to the conveying line ranged about from 0.5 to 3 bar gauge. The maximum gas flow rate used was about $70 \mathrm{~m}^{3} / \mathrm{h}$, which gave approximately $13 \mathrm{~m} / \mathrm{s}$ inlet gas velocity of gas only. The minimum gas flow rate was about $20 \mathrm{~m}^{3} / \mathrm{h}$ used for the metal powder and about $10 \mathrm{~m}^{3} / \mathrm{h}$ for lime and magnesium powder. For each different type of material, the minimum gas flow rate achieved was different.

\subsection{Test materials}

Three types of sample materials were tested, comprising calcium silicide ("CS") metal alloy powder, lime powder and magnesium granules. The particle sizes of all test samples were measured by mechanical sieves (woven wire mesh sieves 200mm diameter used in a Rotex Gradex 2000 particle size analysers) and are shown in Figure 4.

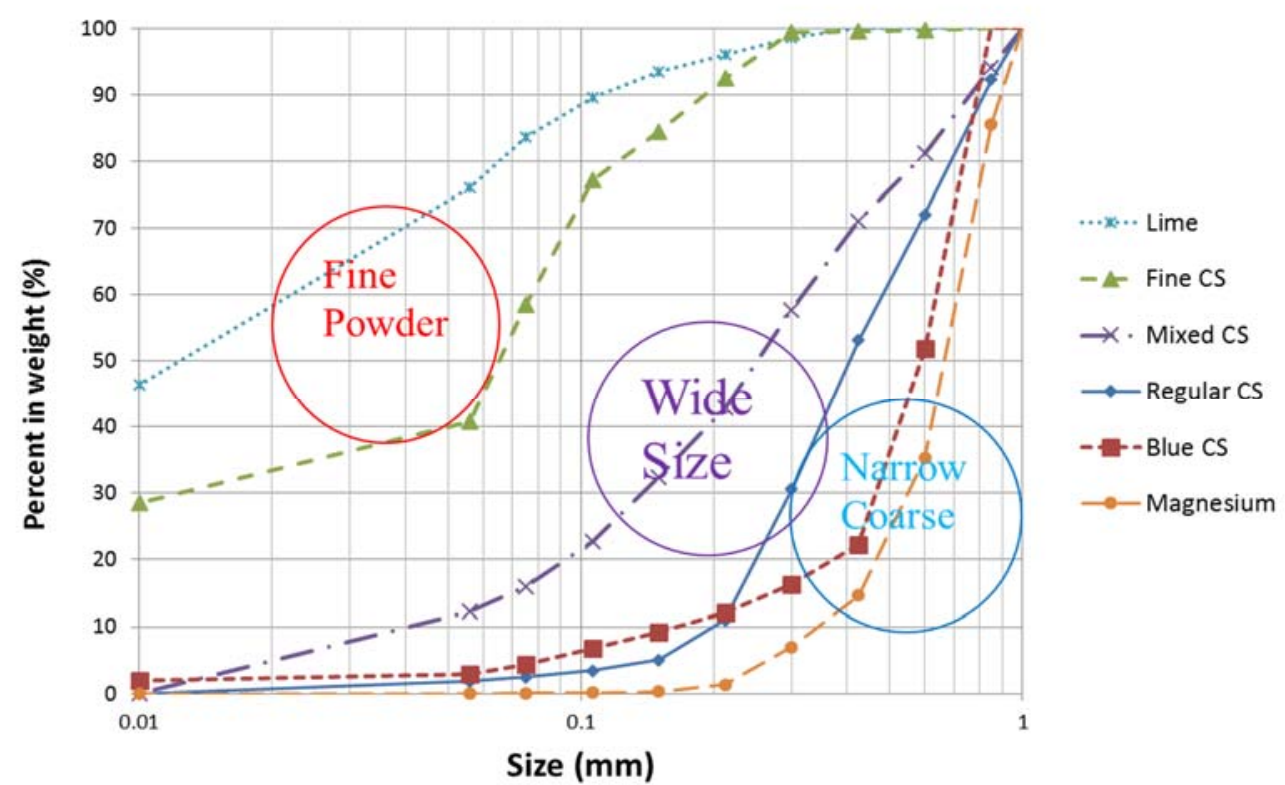

Figure 4: Three groups of sample materials with different particle size distributions 
They all had similar particle shape (angular). The particle density of the metals were similar (magnesium $1740 \mathrm{~kg} / \mathrm{m}^{3}$. CaSi $2500 \mathrm{~kg} / \mathrm{m}^{3}$ ) but quicklime is higher at $3300 \mathrm{~kg} / \mathrm{m}^{3}$. The choice of materials was driven principally by the range of materials that would be expected to be conveyed in practice in the steel ladle alloying ingredient injection process, but exploring the effect of various different size distributions which were available in the CS material.

In terms of particle sizes, the CS metal powder was used in four size categories, i.e. fine, mixed, regular and coarse ("blue" - a commercial grade name) materials. Lime (quicklime) was very fine, D50 around $12 \mu \mathrm{m}$, and magnesium was quite coarse with a quite narrow size range and D50 of about $650 \mu \mathrm{m}$. Fine CS, D50 was about $65 \mu \mathrm{m}$ and smaller than $300 \mu \mathrm{m}$. Mixed and regular CS metal powders had generally wide size ranges with D50 of $250 \mu \mathrm{m}$ and $400 \mu \mathrm{m}$ respectively. The coarse "blue" CS metal powder was close to the magnesium powder in median particle size (both D50 close to $600 \mu \mathrm{m}$ ), both with relatively narrow size distribution but the magnesium narrower than the blue CS.

Most of the materials, for example "CS" metal powders, contain metallic calcium, making them highly sensitive to atmospheric moisture (risk of hydrogen evolution) so the materials had to be conveyed in a dry, and inert (low oxygen) atmosphere. The same requirement applied to the magnesium powder. The quicklime was also highly sensitive to atmospheric moisture which causes hydration, so also needed to be handled in a dry atmosphere. Therefore nitrogen gas was used for all conveying work.

3.1 Observation of minimum conveying gas velocity and slugging/blocking behaviour

- For the broad size range material the minimum conveying velocity was around $5.6 \mathrm{~m} / \mathrm{s}$ (this being the bottom of the lean phase region in this pipe size); as soon as there was any sign of slugging (indicated by movement of the rubber hose loop) the pipeline blocked, and increases in pressure would not move the material - the pipeline had to be broken and cleared manually.

- By contrast, for both fine powders (lime and CS fine), the minimum conveying velocity dropped down to $2.3 \mathrm{~m} / \mathrm{s}$ showing fluidised dense phase flow indicated by gentle movement of the rubber hose at velocities below the transition around $5 \mathrm{~m} / \mathrm{s}$. However, once the air velocity dropped too low (below $1 \mathrm{~m} / \mathrm{s}$ for lime and below $2.3 \mathrm{~m} / \mathrm{s}$ for the fine CS) flow would stop, and the line then blocked - applying higher air flow simply caused surging pressure, and the pipeline could be cleared only by dismantling.

- The magnesium powder showed a third distinct behaviour, with much more movement of the rubber hose loop once air velocity fell below about $5 \mathrm{~m} / \mathrm{s}$, indicating clearly a low velocity slug flow. The minimum conveying velocity was literally zero without blocking the conveying line, in that air could be turned off completely, the material left in the pipeline indefinitely and then conveying would restart when the air was re-applied.

\subsection{Analysis of dense phase conveying behaviour}

For the materials tested, it was clearly shown that the conveying properties of the material fall into three groups as shown in Table 1; 'lean phase only' materials, 'fluidised dense phase' materials and 'low velocity slug flow' materials. Within each group, there are modest differences in the minimum conveying gas velocity, but quite large differences in the relationship between pressure drop and throughput for a given gas flow.

'lean phase only' materials: The results showed that the materials with a broad size such as mixed CS powder and regular CS powder, and even the relatively narrower distribution coarse blue CS powder, 
could be conveyed in a lean phase flow only, down to the border of the onset of slugging. Once the gas velocity was insufficient to suspend the flow, around $5-6 \mathrm{~m} / \mathrm{s}$ for the materials tested, violent slugging set in (shaking of the rubber pipe loop) and the pipeline blocked. The blockage could not be cleared with gas flow or pressure alone. For these materials, highest throughput occurred with a gas flow that gave a pipeline inlet gas velocity just above the minimum value.

6 'Fluidised dense phase' materials: The fine materials such as lime and fine CS powder could be 7 conveyed in a fluidised dense phase flow (gentle movement of the rubber pipe loop) as well as dilute 8 phase, down to much lower air velocities. However, once they block the pipeline, the blockage cannot 9 be cleared with gas flow. For these materials, the maximum throughput was much higher but again occurred with the lowest usable gas flow, again just above the minimum velocity.

'Low velocity slug flow' materials: Only the magnesium behaved in this way. It could be conveyed in low velocity dense phase slug flow (much more movement of the rubber pipe loop) as well as lean phase, having no minimum conveying gas velocity. For this material the highest throughput occurred with a gas flow just above the minimum for lean phase flow, with lower velocities (slug flow) giving greatly reduced throughput by a factor of around 3 or 4 to 1 . The detailed conveying characteristics can be subdivided into 3 groups and results are shown as follows.

Table 1: Breadth of material size distributions and their conveying-ability

\begin{tabular}{|c|c|c|c|c|c|c|c|c|}
\hline Materials & $\begin{array}{l}\text { D10 } \\
(\mu \mathrm{m})\end{array}$ & $\begin{array}{l}\text { D50 } \\
(\mu \mathrm{m})\end{array}$ & $\begin{array}{l}D 90 \\
(\mu \mathrm{m})\end{array}$ & D90 / D10 & $\begin{array}{c}\text { Fines } \\
<30 \mu \mathrm{m} \\
(\%)\end{array}$ & $\begin{array}{c}\text { Lean \& } \\
\text { Fluidised } \\
\text { dense } \\
\text { phase flow }\end{array}$ & $\begin{array}{l}\text { Lean } \\
\text { phase } \\
\text { only }\end{array}$ & $\begin{array}{c}\text { Lean \& } \\
\text { low } \\
\text { velocity } \\
\text { slug flow }\end{array}$ \\
\hline Lime & Unknown & 12 & 105 & $\begin{array}{c}\text { Unknown } \\
>11\end{array}$ & 65 & $x$ & & \\
\hline Fine CS & Unknown & 65 & 195 & $\begin{array}{c}\text { Unknown } \\
>11\end{array}$ & 37 & $x$ & & \\
\hline Mixed CS & 40 & 240 & 750 & 18.8 & 8 & & $x$ & \\
\hline Regular CS & 200 & 400 & 800 & 4.0 & 2 & & $x$ & \\
\hline Blue CS & 170 & 600 & 780 & 4.6 & 3 & & $x$ & \\
\hline Magnesium & 340 & 650 & 900 & 2.6 & 0 & & & $x$ \\
\hline
\end{tabular}

\subsection{Fine particulates (lime and fine CS powder)}

There are two tested materials that can be in this category, lime and fine CS. In Figure 4, it can be found that both of these materials had a large proportion of fine particulates. For lime, pressure drop in conveying line and conveying characteristics are show in Figure 5 and 6.

The test shows that lime can be conveyed in a dense phase flow with very gentle slugging (appearing to be a smooth fluidised dense phase mode) right down to a very low gas flow rate. In the tests, the lowest gas flow rate used was about $10 \mathrm{~m}^{3} / \mathrm{h}$ of nitrogen, which give a minimum conveying velocity of $1.0 \mathrm{~m} / \mathrm{s}$ at a high pressure drop of a little under 3 bar gauge. With this minimum gas flow rate, the solids flow rate reached a maximum of $240 \mathrm{~kg} / \mathrm{min}$. 
For fine CS powder, pressure drop in conveying line and conveying characteristics are shown in figure

Figure 5: Total pressure drops in the conveying line versus solid flow rates for lime

The data in the above graph was interpolated to produce a form of conveying characteristics popularly presented by many authors, shown in fig. 6 below:-

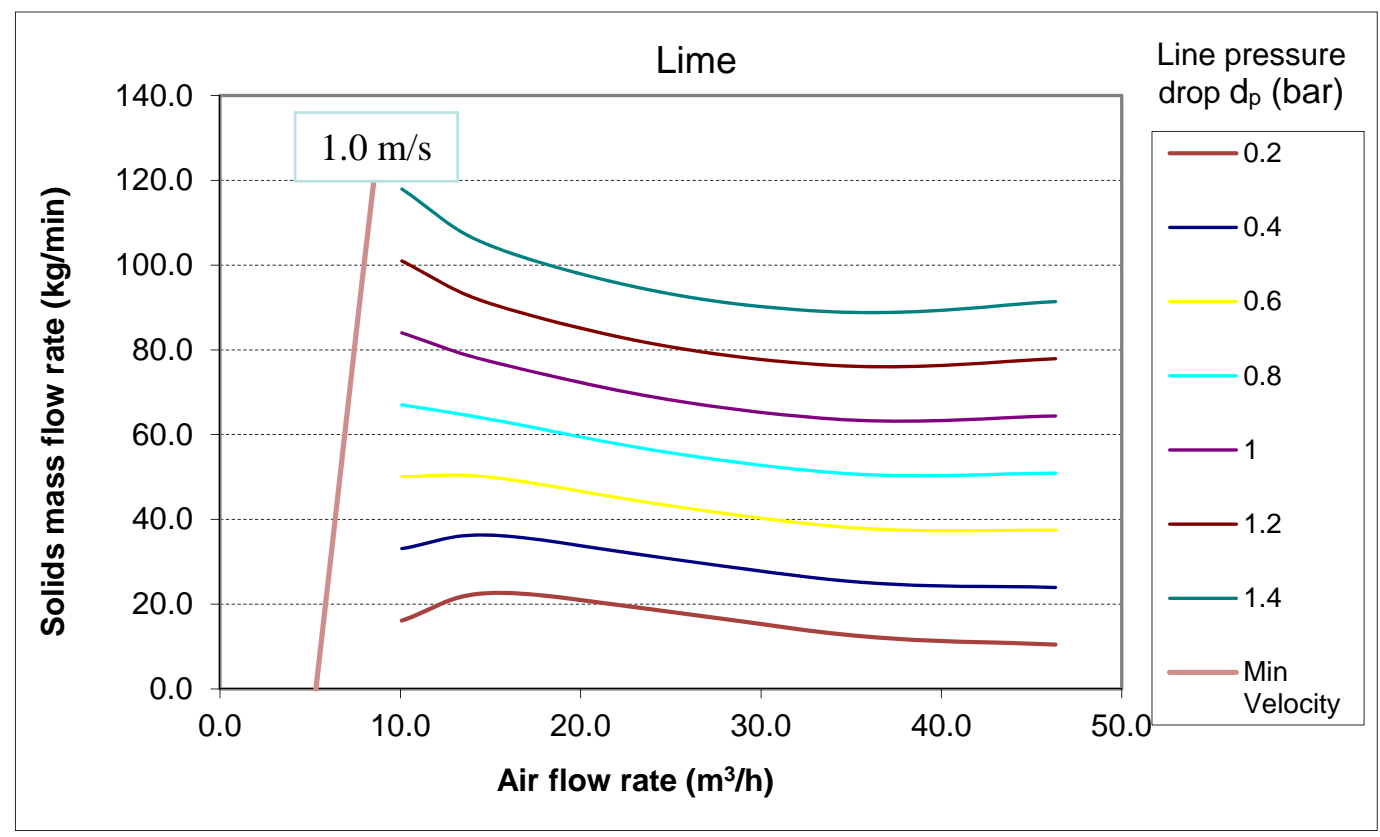

Figure 6: Conveying characteristics of lime with minimum conveying velocity of $1 \mathrm{~m} / \mathrm{s}$

7 and 8 . The fine CS powder also contains a big proportion of fine particles.

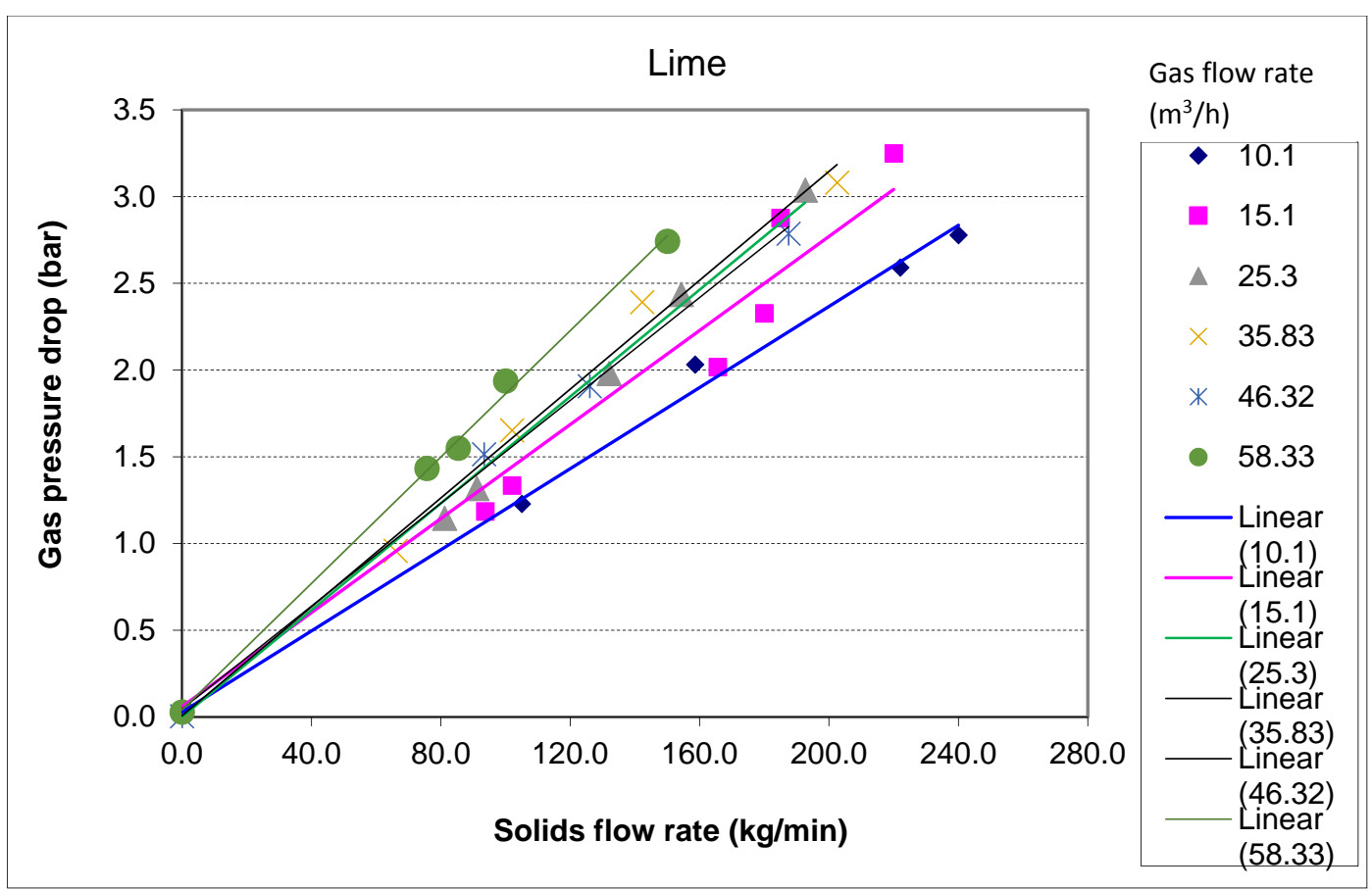




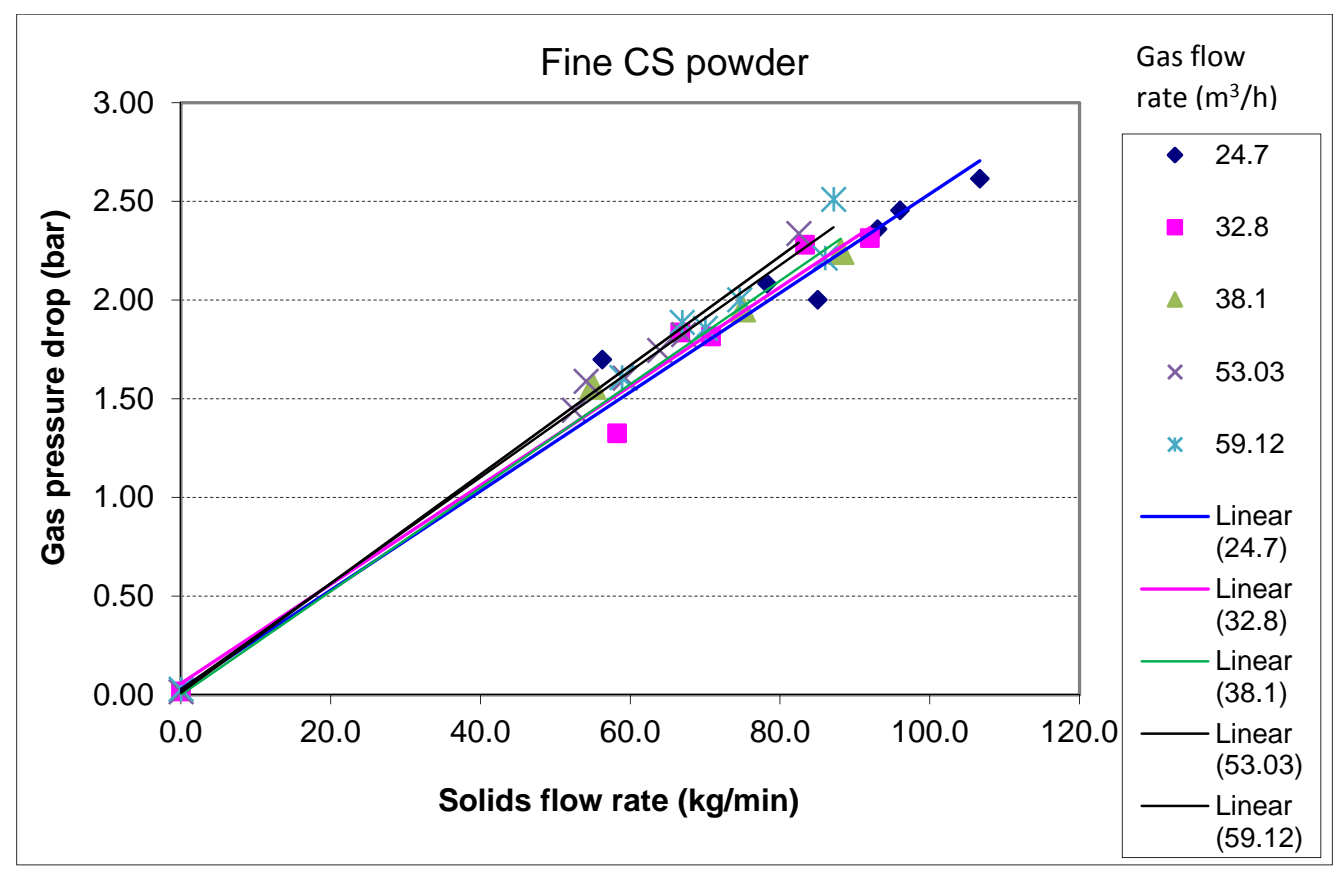

Figure 7: Total pressure drops in the line versus solid flow rates for fine CS powder

As the gas velocity was reduced, this material made a steady transition from smooth dilute suspension flow into a dense phase flow with gentle slugging (appeared to be a smooth, fluidised dense phase mode). The minimum conveying velocity achieved in the tests was about $2.3 \mathrm{~m} / \mathrm{s}$, at which velocity the maximum solids flow rate of $106 \mathrm{~kg} / \mathrm{min}$ was achieved with the highest pressure drop in the conveying line of around $2.6 \sim 2.7$ bar at a gas flow rate of $23 \mathrm{~m}^{3} / \mathrm{h}$.

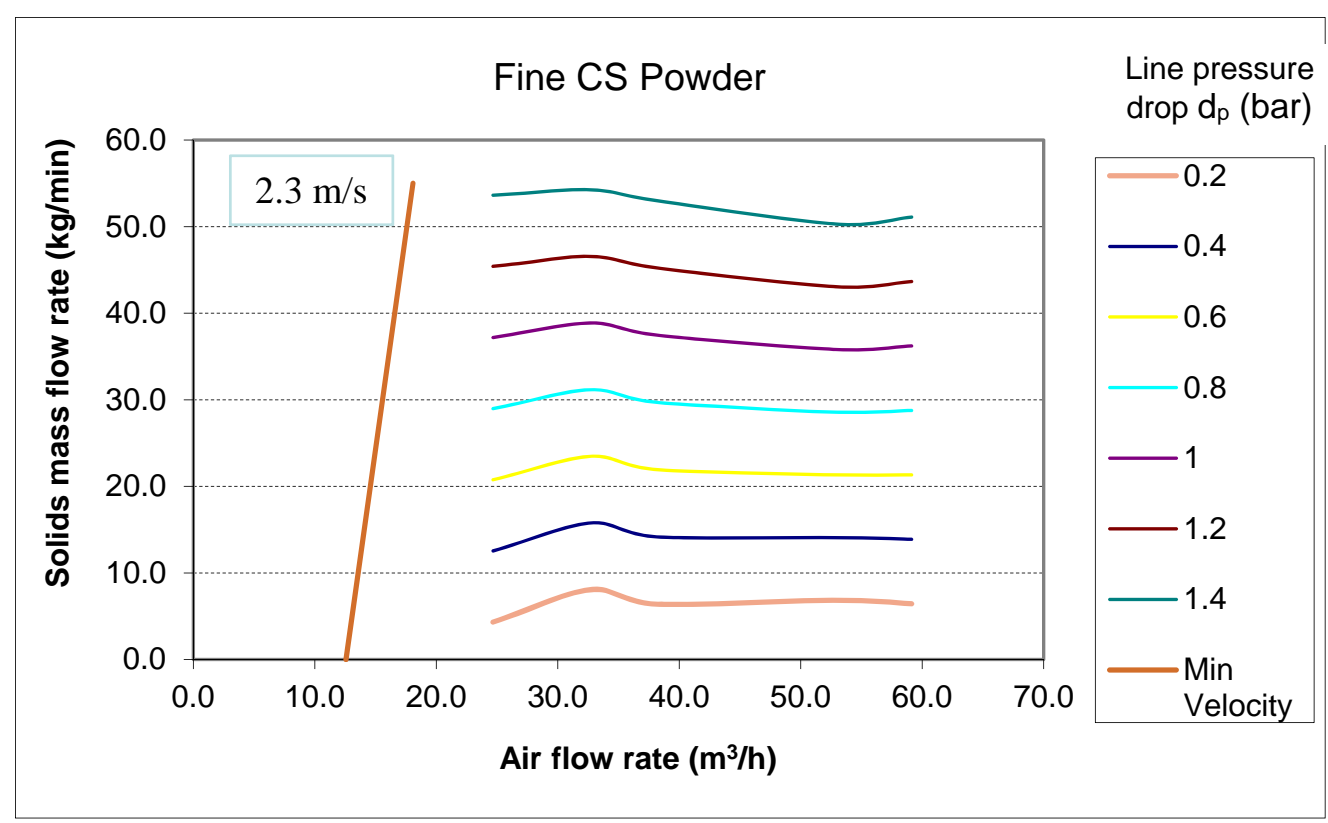

Figure 8: Conveying characteristics of fine CS powder with a minimum conveying velocity of $2.3 \mathrm{~m} / \mathrm{s}$ 


\subsection{Particulates with a wide size range}

2 As seen in Figure 4, three materials can be classified in this category, i.e. mixed CS, regular CS and 3 coarse "blue" CS powders. Generally the materials have a wide range of particle size with a certain 4 proportion of fine particles. For regular CS and coarse blue CS, size of D10 is about $200 \mu \mathrm{m}$ and for 5 mixed CS D10 is only about $50 \mu \mathrm{m}$. However D90 for all three materials is about $800 \mu \mathrm{m}$. For mixed CS 6 powder, pressure drop and conveying characteristics are show in Figure 9 and 10.

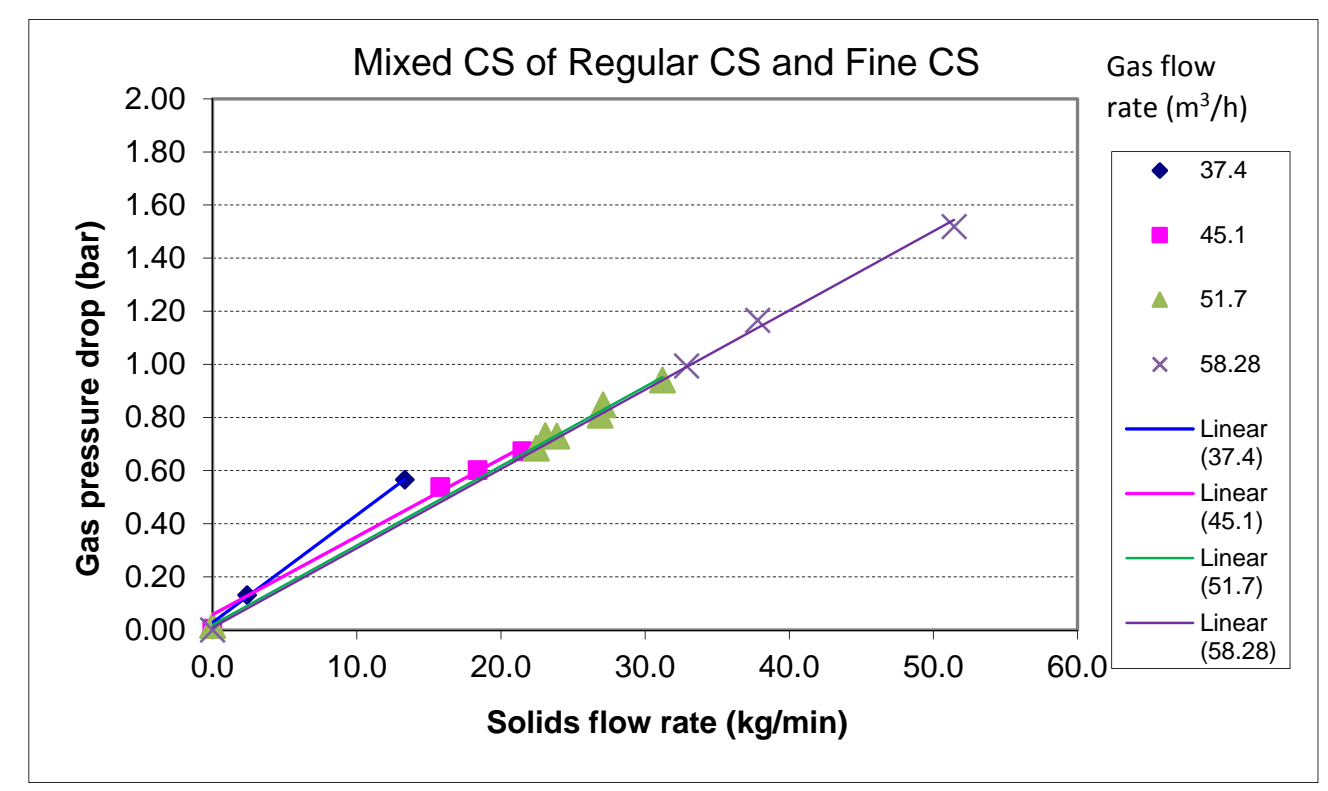

Figure 9: Total pressure drops in the line versus solid flow rates for mixed CS powder

The results show that the maximum pressure drop reached was only about 1.5 bar and the minimum conveying velocity was $5.6 \mathrm{~m} / \mathrm{s}$, making this material only suitable for lean phase pneumatic conveying.

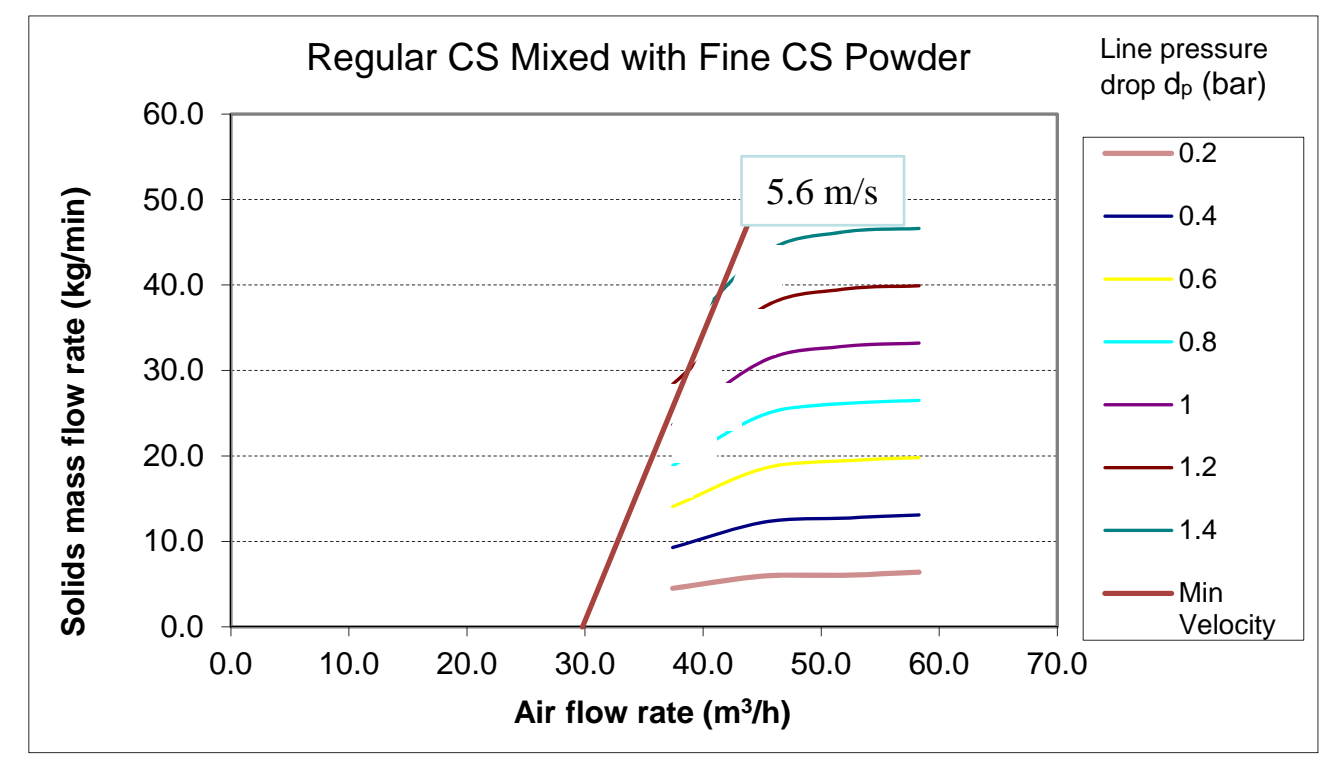

Figure 10: Conveying characteristics of mixed CS with a minimum conveying velocity of $5.6 \mathrm{~m} / \mathrm{s}$ 
For regular CS powder, pressure drop in conveying line and conveying characteristics are shown in figures 11 and 12. In Figure 4, it can be seen that the regular CS powder contains less fines and has a fairly narrow size range $(D 50=400 \mu \mathrm{m})$. In Figure 11 , it can be seen that substantially higher maximum pressure drop of about 2.7 bar was achieved at a solid flow feeding rate of about just less than 50 $\mathrm{kg} / \mathrm{min}$. This was mainly due to a lower minimum conveying velocity for this material of $4.1 \mathrm{~m} / \mathrm{s}$. It is also noted that with this material, the highest throughput occurred with a more moderate gas flow (the lower values used); with higher gas flow rates, the pressure drops went up but the solids flow rate did not go up, due to the form of the conveying characteristics of the material.

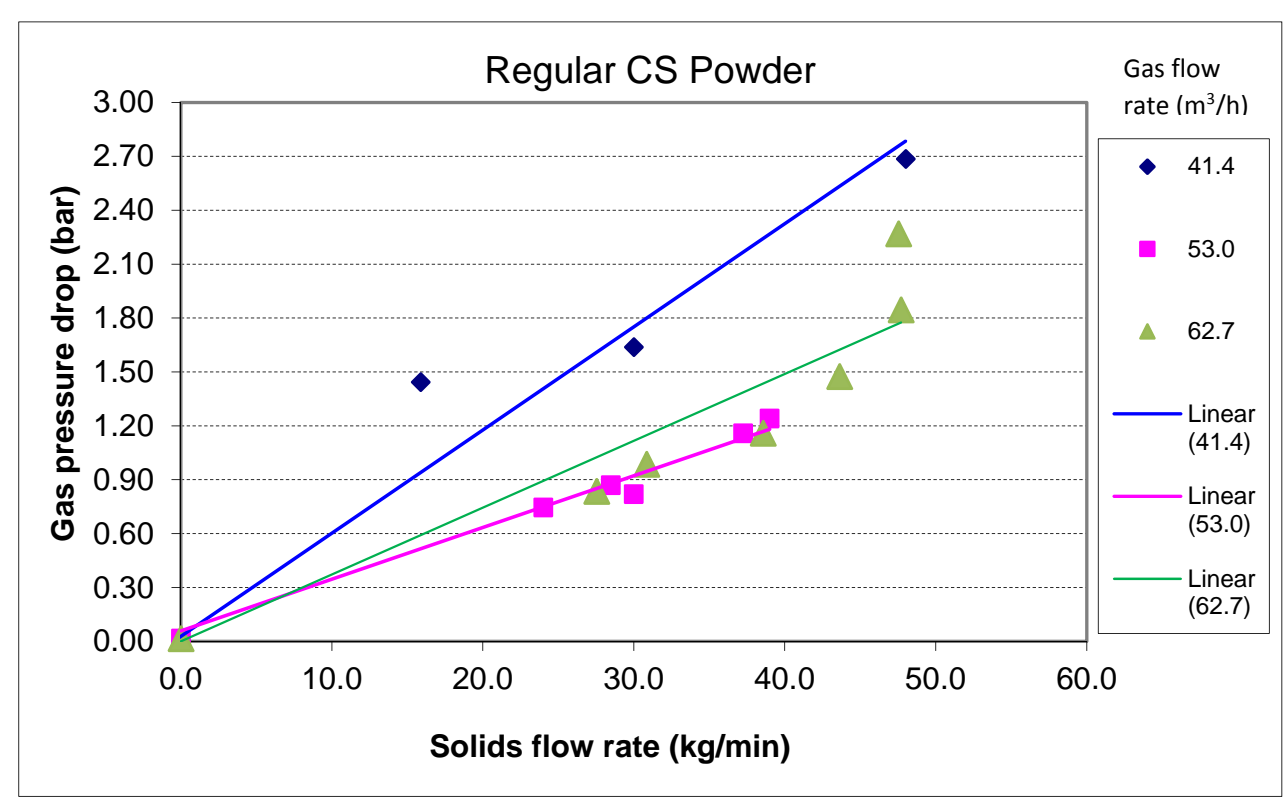

Figure 11: Total pressure drops in the line versus solid flow rates for regular CS powder

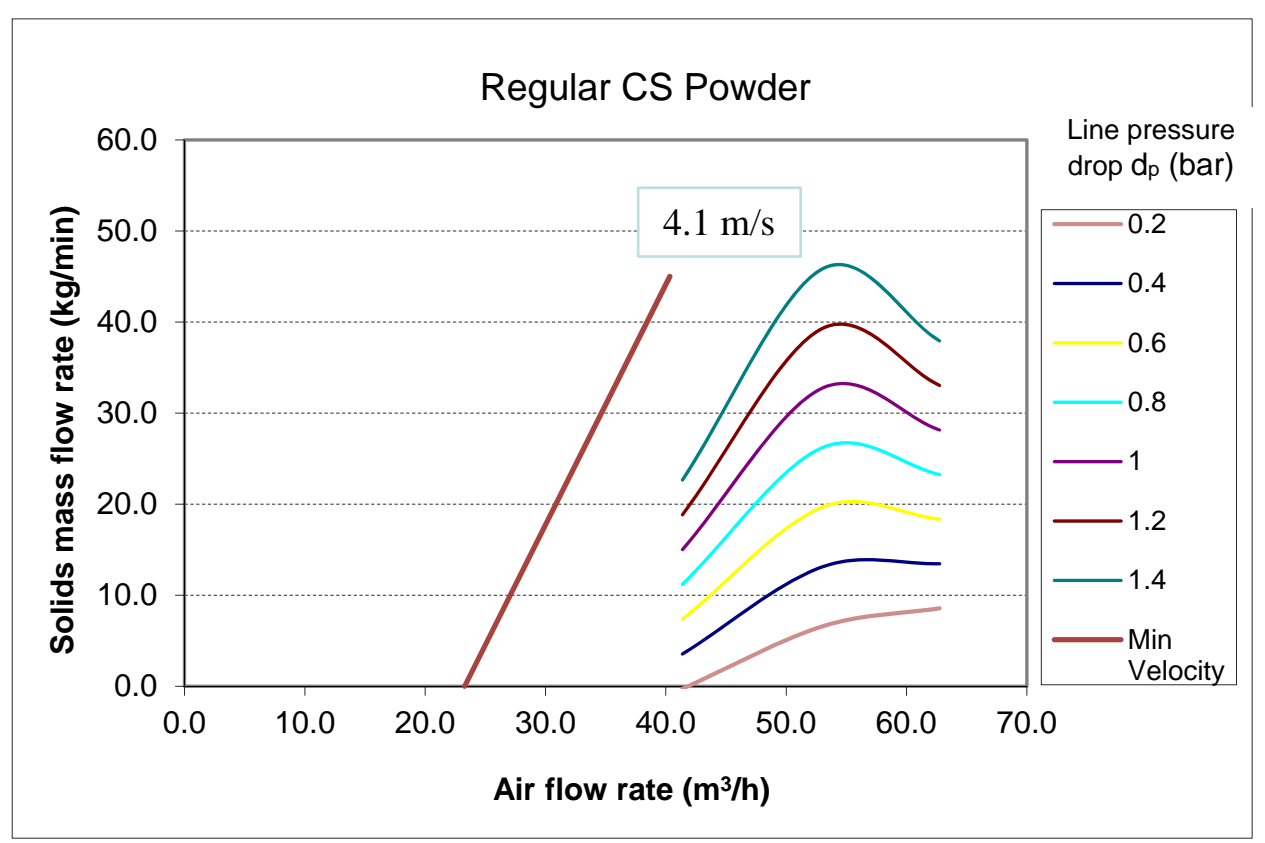


The conveying measurement results for coarse blue CS are in Figure 13 and 14 below. Figure 4 shows coarse blue CS spans the same size range as the regular CS, but with less fines, with a D50 at about $600 \mu \mathrm{m}$. This material is obviously a lot coarser than the other two materials. The results in Figure 14 showed a minimum conveying velocity for this material of $5.7 \mathrm{~m} / \mathrm{s}$ at a solids flow rate of about 40

$5 \mathrm{~kg} / \mathrm{min}$ with a total line pressure drop of $1.3 \mathrm{bar}$. The minimum gas flow rate used was about $44 \mathrm{~m}^{3} / \mathrm{h}$ 6 but the highest solids flow rate was achieved with the maximum gas flow rate used for this material.

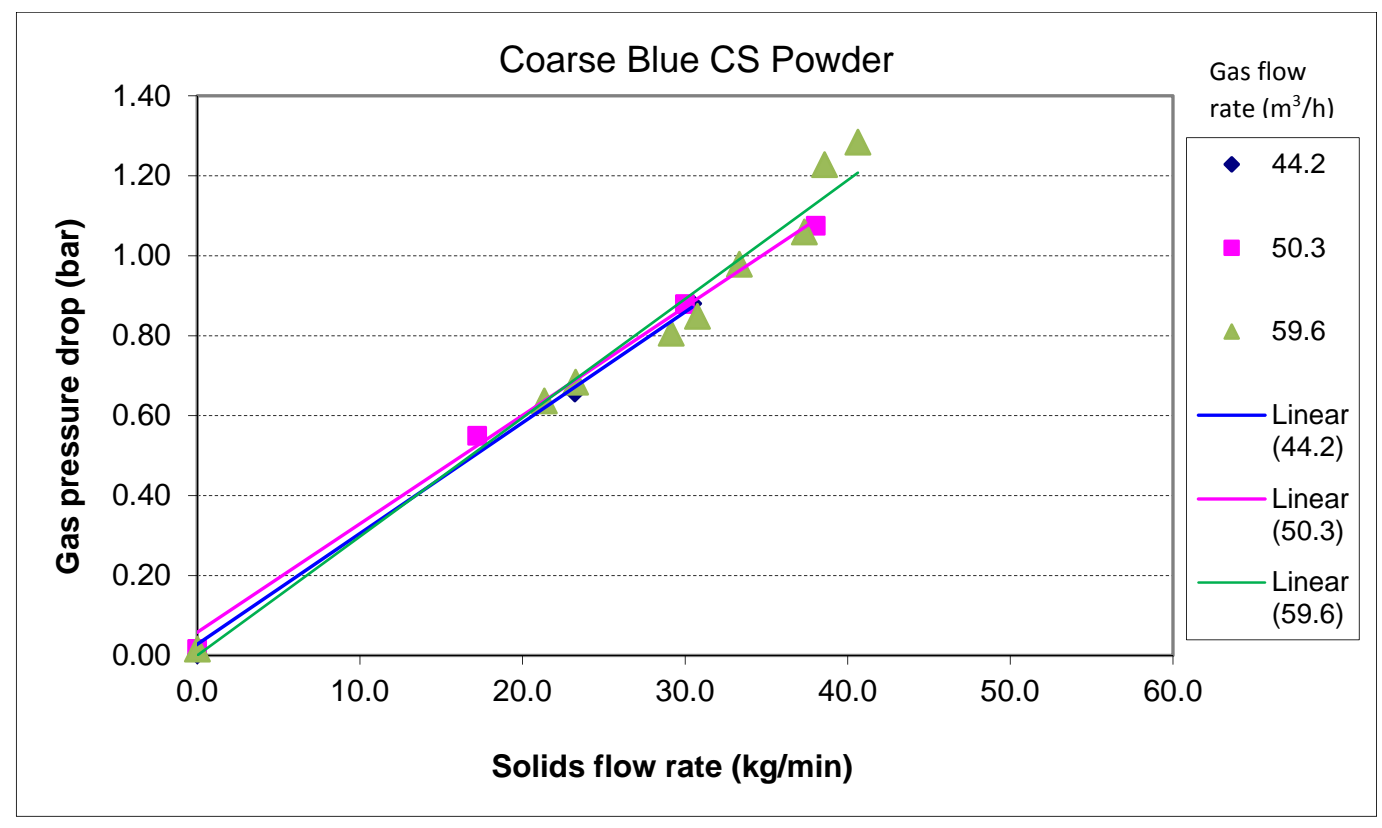

Figure 13: Total pressure drops in the line versus solid flow rates for coarse blue CS powder

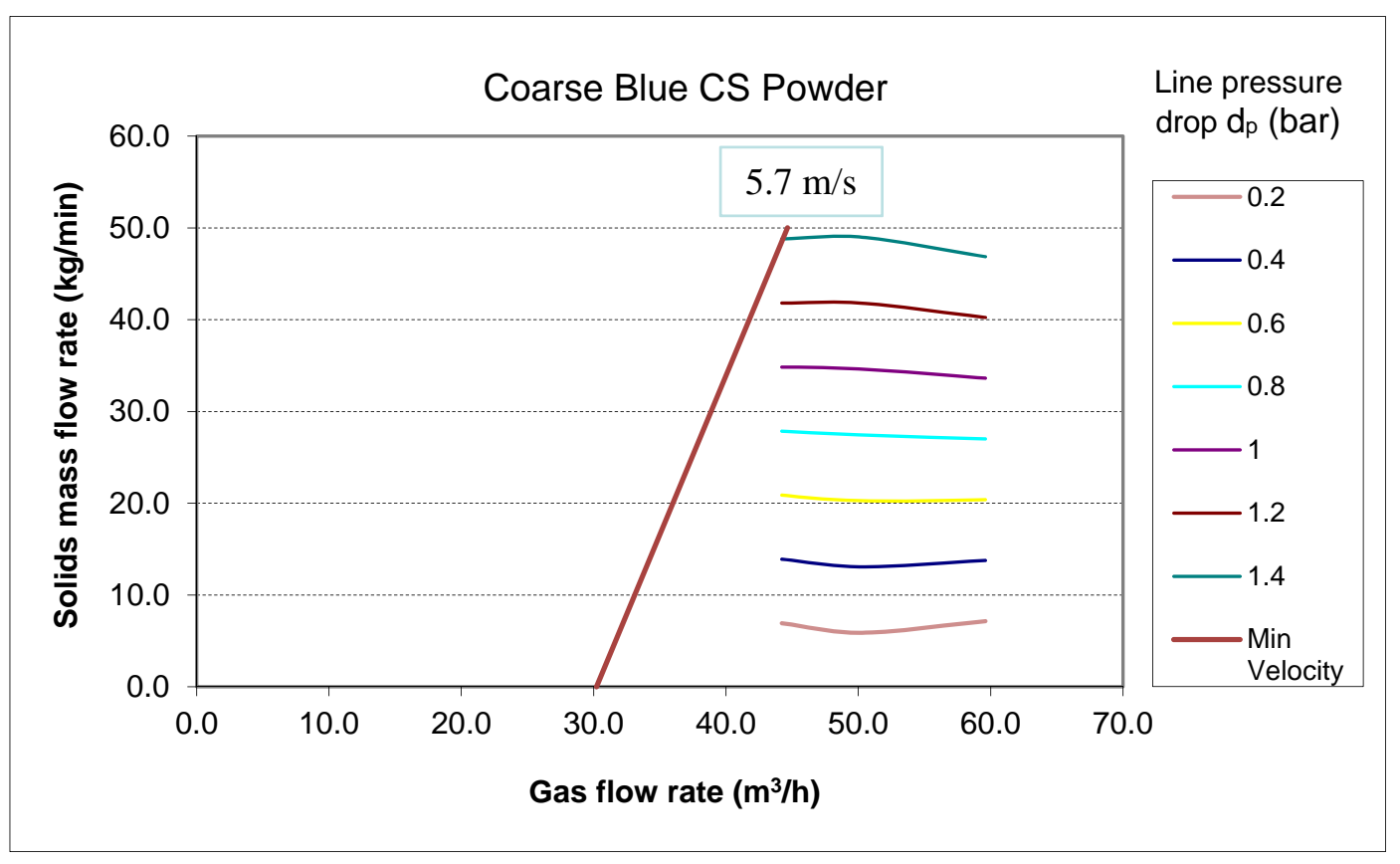




\subsection{Coarse particulate with a very narrow size range}

2 In Figure 4, it shows magnesium had a fairly narrow range of particle size with a D50 of $650 \mu \mathrm{m}$ and 3 size range between $350 \mu \mathrm{m}$ (D10) and $900 \mu \mathrm{m}$ (D90). It shows the magnesium tested was highly 4 permeable. The tests showed that this material can very easily support a low velocity slug flow mode 5 of dense phase conveying. There was no minimum conveying velocity for this material. At any time 6 the conveying process could be shut down and re-started again by turning off and switching on the 7 gas supply (this was impossible with any of the other materials tested). The conveying measurement results for magnesium are in Figure 15 and 16.

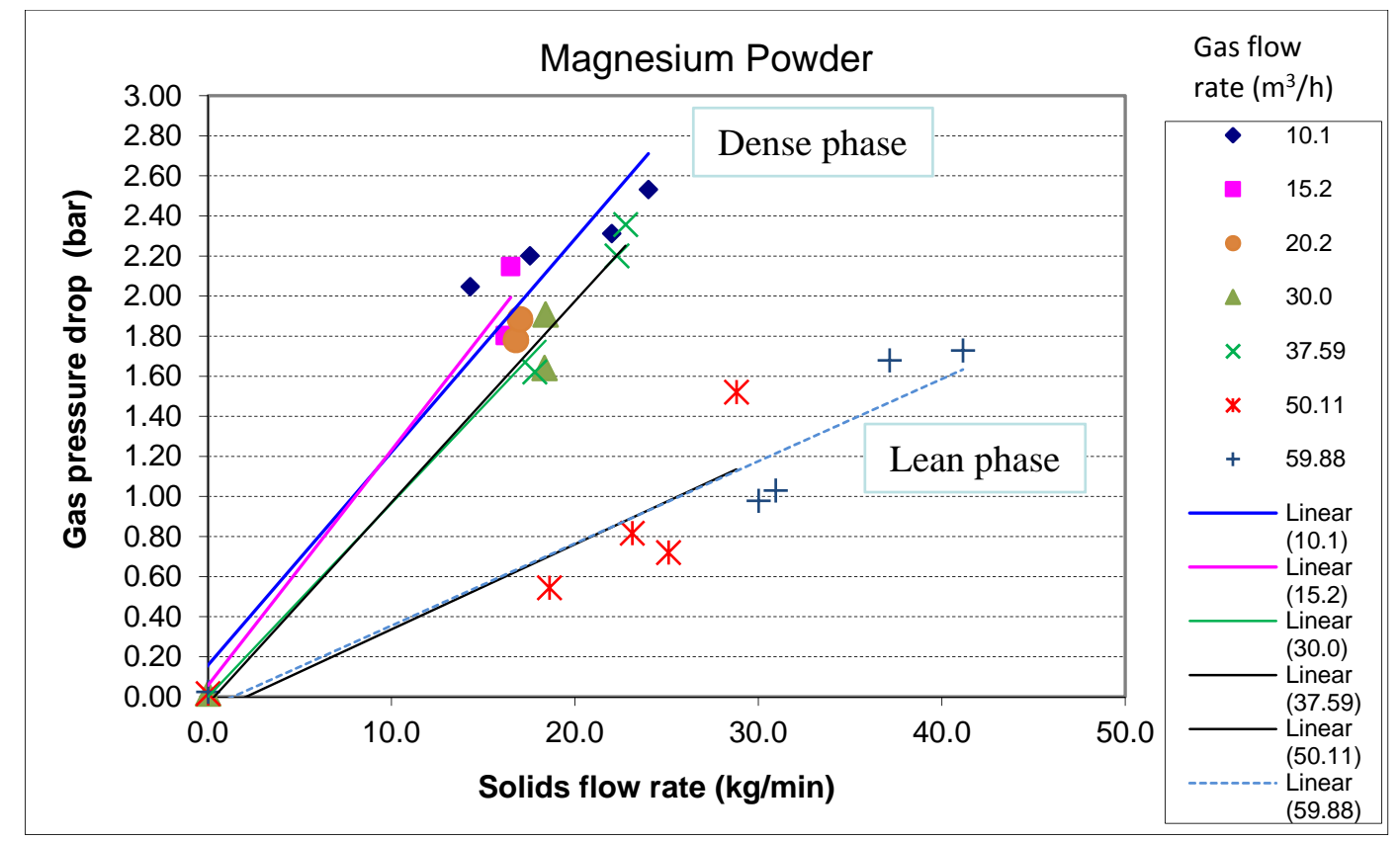

Figure 15: Total pressure drops in the line versus solid flow rates for magnesium powder

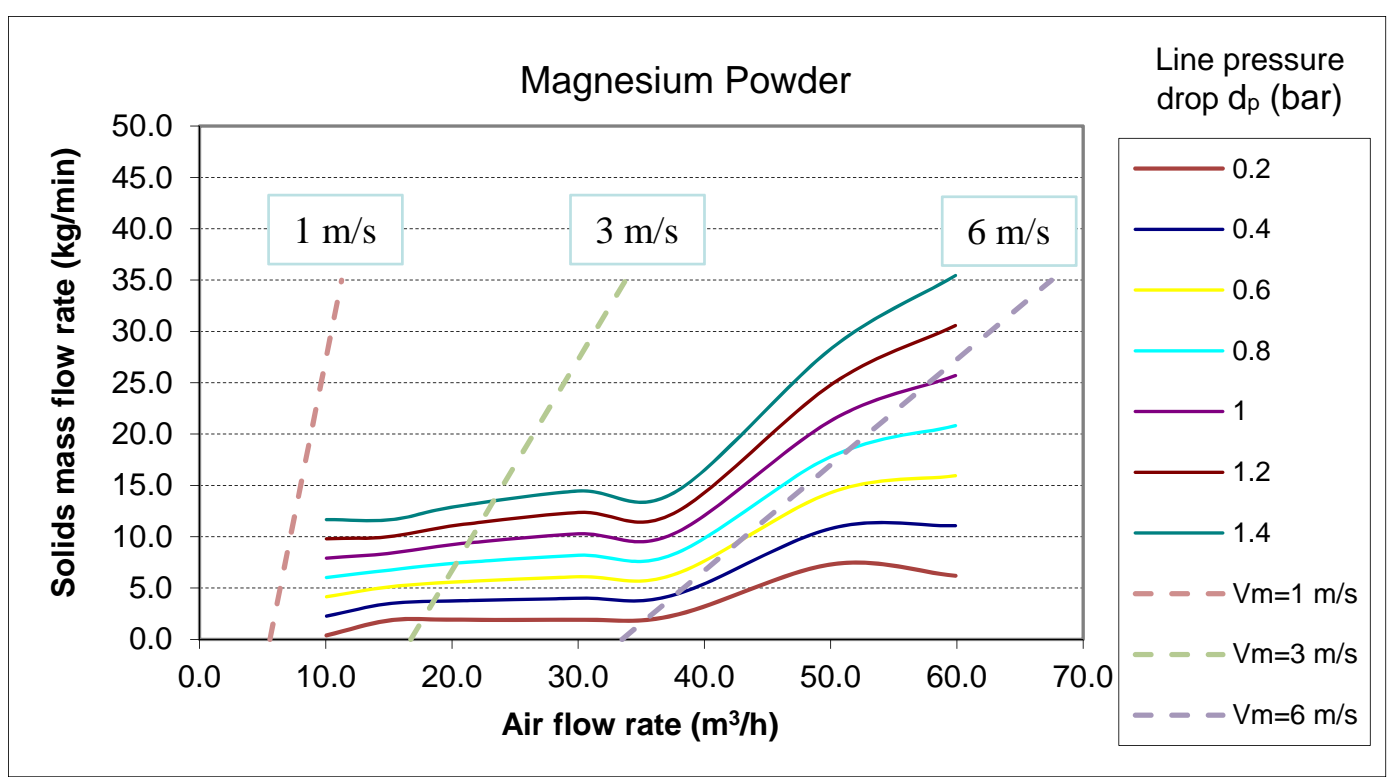

Figure 16: Conveying characteristics of magnesium powder with zero minimum conveying velocity 
For magnesium powder, the low velocity slug flow allowed flow with high pressure drop and low air flow rate, but with low solids flow rate. This is a distinctly different pattern of behaviour from the fine powders which exhibited high flow rates with high pressure, low gas flow conditions. With higher gas flow rates, the solid flow rates did not change significantly until lean phase conveying was achieved. The maximum solids flow rate achieved was about $40 \mathrm{~kg} / \mathrm{min}$ with a gas flow rate of $60 \mathrm{~m}^{3} / \mathrm{h}$, in lean phase transport, and only around $12-15 \mathrm{~kg} / \mathrm{min}$ in low velocity slug flow.

8 For pneumatic conveying of solid particulate materials, it is noted that for a certain pipe route, a pressure drop for different materials conveyed, as well as a different blocking point. Particularly if the solids feed rate needs to be maximised, the system gas flow rate needs to be set up to give the optimum performance, which will be at a different condition for the different materials. For materials that support only lean phase flow, and for materials that support a fluidised-dense-phase flow, maximising the solids loading of the flow by minimising the gas flow rate will be the best option for effectively operating the conveying system with minimum gas usage and maximum throughput; fortuitously, for such materials this will also be the condition that will give minimum wear and minimum particle degradation. By contrast, the material that supported low velocity slug flow gave much lower solids flow at the low velocities, leading to a trade-off between the beneficial advantages of low velocity flow (low degradation and low pipe wear), against reduced throughput (for a given pipe size) and poorer efficiency.

Looking at this from a design standpoint requiring a given throughput;

- For fine powders that support fluidised dense phase flow, changing to dense phase from lean will result in smaller pipelines, lower air flow and probably reduced energy consumption.

- By contrast, for those coarser, narrow distribution materials that support low velocity slug flow, changing to dense phase from lean will necessitate larger pipe bore, higher total air flow and pressure and therefore increased energy consumption.

Clearly, in all cases, accurate control of gas flow rates is essential for a stable and efficient conveying condition with different materials because of their different conveying characteristics. Therefore by variable control of gas flow rates, it is still possible to achieve a steady, reliable and optimised conveying condition if the material conveying characteristics change.

These three groups of 'conveying ability' of the materials tested, 'lean phase conveyable only', 'fluidised dense phase conveyable', and 'low velocity slug flow dense phase conveyable' materials, completely reflect the findings of Jones, Mainwaring, Mills, and Reed, etc. in the 1980's [6-9, 16, 17] (see Figure 17) and although little work has been done since then to further our insight into the fundamentals, the intervening years of experience have shown these to be a set of groupings that in practice do encompass all of the materials commonly met with in pneumatic conveying.

In Table 1, it is noted that the two 'dense phase' groups can also be conveyed in lean phase as well, which means all the materials tested can be conveyed in lean phase flow. For the pipeline used, it appears to be above about $6 \mathrm{~m} / \mathrm{s}$ for the materials tested, which is lower than would be expected in most industrial systems of typically $80-300 \mathrm{~mm}$ bore, but many studies have shown that the transition velocity is lower in smaller pipelines. For the 'fluidised dense phase conveyable' materials, the minimum conveying velocity is often very low, but definite; for example, the lime can conveyed at 1.0 $\mathrm{m} / \mathrm{s}$ and the fine CS powder can be conveyed at $2.3 \mathrm{~m} / \mathrm{s}$. With a decreasing gas flow rate, it is normal with fine powders to see the solids feed rates go up for the same line pressure drop. However if the 
1 conveying gas velocity goes lower than the minimum value, the line will be blocked and the blockage cannot be moved easily. In the size distributions of these materials, it can be found that they normally contain a large proportion of fine powder with little coarse; D90 is between 100 and 200 microns for both test materials, and around a third or more is below 10 microns in each case. Such materials usually have very good air retention properties (take a long time to settle once aerated) but once settled are relatively impermeable. The good air retention characteristic allows the material to stay in a liquid-like state all the while it is moving, so it flows like slugs of water through the pipeline; but if it moves too slowly or stops, the air is lost and it becomes impermeable so it blocks the pipe and restarting it is impossible. As long as the material remains fluid due to sufficient speed of movement along the pipeline, reducing gas flow gives increased solids flow for the same pressure drop. Other common materials that have been found in tests to exhibit this behaviour include cement powder, barite powder, fine dry clay, wheat flour and many other fine ground powders.

The magnesium is a unique material within the candidates tested in this study, and falls within the group of 'low velocity slug flow dense phase conveyable' materials. From the particle size analysis, it can be seen that the magnesium powder tested has an unusually narrow size range and is quite coarse, without any fine particles; D10 is between 300 and 400 microns and all particles are below $1 \mathrm{~mm}$. Materials with such a narrow size range have very good gas permeability, due to the open structure and large gaps between the coarse particles. This allows air to pass easily through the structure of a slug inside the pipe, so that a slug is effectively dragged along from the inside due to the pressure drop of the air through the slug. It is typical to find that such materials have no minimum conveying velocity, which means the conveying process for this material can be stopped at any time by switching off the gas supply, and started again simply by increasing the gas flow rate. Other examples of common materials that have been found in tests at The Wolfson Centre to display this behaviour include high quality granular sugar, very closely graded sand and plastic pellets. From these tests, specifically the contrast with the blue CS which has virtually the same D50, as well as from previous experience, it is conclusively proved that the key to dense phase conveyability lies not in the median particle size, but in the narrowness of the distribution.

The materials such as blue CS, regular CS, and mixed CS powders are only able to be conveyed in a lean phase flow. These materials feature wider size distributions (see Figure 4) including significant proportions of both coarse and fine particles (big D90 but still relatively small D10). These materials have relatively poor permeability due to a significant proportion of fines which fill the gaps between the larger particles in the structure, but also they do not retain air very well because they do not have a large proportion of ultrafine material, and do contain significant coarse particles, so that even if they are aerated, the natural movement of a slug along the conveying pipeline is insufficient to keep the air entrained. To convey this sort of material, a high gas flow rate is normally required, to keep the particles in suspension in the air.

For the purposes of comparison against previous work, the properties of the materials have been put on the Dixon Slugging Diagram (see Figure 17). Dixon's thesis was that only materials in groups $A$ and $D$ are conveyable in dense phase; in this study the fine CS was in group A (close to the border with B) but the lime was in group C, yet both were conveyable in dense phase. The "middle" two grades of CS by size were correctly predicted as not dense phase conveyable, but both the coarsest CS and the magnesium fell into group $D$ (predicted as dense phase conveyable), yet the former was not dense phase conveyable whereas the latter was. Probably the most important aspect of this comparison is to reinforce the findings of Mainwaring et al and Jones et al that the dense phase conveying behaviour (or lack of it) is unrelated to the steady state behaviour of a material in a fluidisation column as originally classified by Geldart or subsequently modified by Dixon. 


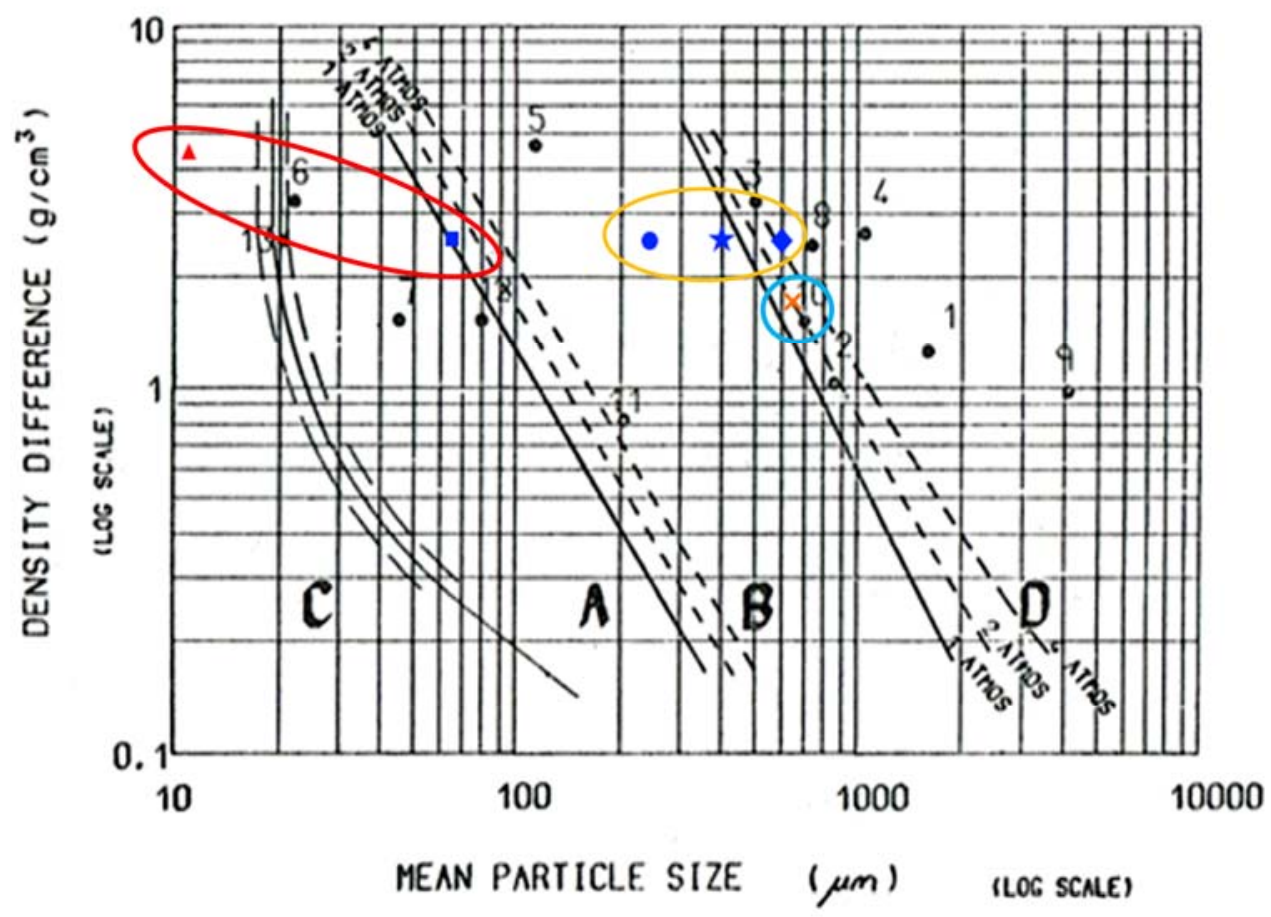

$\Delta$ Lime; $\square$ Fine CS; $\bigcirc$ Mixed CS; $\star$ Regular CS; $\bullet$ Blue CS; $\star$ Magnesium;

Figure 17: Dixon 'slugging diagram' for pneumatic conveying with materials tested in this study

\section{Conclusions}

From this study, it is concluded that particle size distribution of powders critically affects the conveying characteristics in pneumatic conveying of particulate materials. It appears that to support fluidised dense phase flow, the key thing is that the average size of the particles must be small enough, whereas for low velocity slug flow it is the narrowness of the distribution that counts.

\subsection{Size distribution criteria for dense phase conveying}

In regard to the main objective of this research, a criterion can be proposed from the observations, for assessing whether (and if so in what mode) a given material can be conveyed in dense phase, based on knowledge of the size distribution.

1. If a material has a $\mathrm{D} 50<70 \mu \mathrm{m}$ it has a good chance of supporting fluidised dense phase flow - but with a definite minimum air velocity, below which blocking will occur (restarting then being impossible). Such materials will give high throughput with low gas flow and high pressure.

2. If the material has a narrow size range $D 90 / D 10<2.5$ (and is free flowing), it will probably support low velocity slug flow, and be restarted from a "full line" shutdown. Such materials will give low throughput under low gas flow, high pressure conditions.

3. If the material satisfies neither of these criteria, it is likely to block the line at air velocities below the saltation velocity, so conveying will be lean phase only. 
Finally, between the different groups, the minimum conveying gas velocity is very different, but the materials within each group have broadly similar minima and patterns of behaviour.

Potential users of these criteria should remember that whilst there are no reasons to suppose that the size distribution criteria for available modes of flow would change with pipe size and layout, the gas velocities at which the transitions occur will certainly be higher in larger pipes.

\subsection{Further work indicated}

These disparate behaviours observed between the three groups of materials tested are commensurate with tendencies observed previously for other materials, and are linked to the size distributions. The above criteria are recommended to be used for the time being, but further review of historic conveying properties data and size distributions will be undertaken to see whether the criteria can be refined further.

\section{Acknowledgement}

The authors would like to acknowledge the SMS Mevac UK Ltd for their funding of the research and supply of test materials.

\section{References}

1. Mills D., Pneumatic Conveying Design Guide (Third Edition), Butterworth-Heinemann, 2015,

2. Klinzing G.E., Rizk F., Marcus R., Leung L.S., Pneumatic conveying of solids: a theoretical and practical approach, $3^{\text {rd }}$ Ed., Springer Science \& Business Media, 2011

3. Klintworth, J., Marcus, R.D.: A review of low velocity pneumatic conveying systems, Bulk Solids Handling (1985 August), Pages 747-754

4. Geldart D, Types of Gas Fluidisation, Powder Technology, Volume 7, 1973, Pages 285-292

5. Dixon G, The Impact of Powder Properties on Dense Phase Flow, Proc Int. Conf. on Pneumatic Conveying, London, Jan 1979

6. Mainwaring NJ, Reed AR, An appraisal of Dixon's slugging diagram for assessing the dense phase conveying potential of bulk solid materials, $3^{\text {rd }}$ Int. Conf. on Pneumatic Conveying Technology “Pneumatech 3", 24-26 March 1987, Jersey, Channel Islands,

7. Hitt RJ, An Investigation into the Low Velocity Pneumatic Conveying of Bulk Materials, PhD thesis, Thames Polytechnic, London, UK, December 1984

8. Mainwaring NJ, The effect of the physical properties of bulk solid materials on modes of dense phase pneumatic conveying, PhD thesis, Thames Polytechnic, London, UK, 1988

9. Jones MG, The influence of bulk particulate properties on pneumatic conveying performance, PhD thesis, Thames Polytechnic, London, UK, 1988

10. Sperl $M$, Experiments on corn pressure in silo cells - translation and comment of Janssen's paper from 1895, Granular Matter, May 2006, Volume 8, Issue 2, pp 59-65

11. Tomasetta I, Barletta $D$, Lettieri $P$, Poletto $M$, The measurement of powder flow properties with a mechanically stirred aerated bed, Chemical Engineering Science, Volume 69, 2012, Pages 373-381

12. Guo, X., Lu, W., Lu, H., Cong, X., Xie, K., Liu H. and Gong X., Pressure drop prediction for horizontal dense-phase pneumatic conveying of pulverized coal associated with feeding to gasifier, Chemical Engineering Research and Design 91, 2013, Pages 2509-2514

13. Mallick, S.S., Wypych, P.W., An investigation into modelling of solids friction for dense-phase pneumatic conveying of powders. Particulate Science and Technology, 28 (2010), 51-66 
14. Setia G., Mallick S.S., Pan R., Wypych P.W., Modelling minimum transport boundary for fluidized dense-phase pneumatic conveying systems, Powder Technology, Volume 277, 2015, Pages 244-251

15. Deepak Kumar, An investigation into modelling solids friction for dense phase pneumatic conveying system, PhD thesis, Thapar University, Patiala, India, 2014

16. Jones, M.G. and D. Mills, Product classification for pneumatic conveying, Powder Handling and Processing, (1990.2), Pages 117-122

17. Mainwaring, N. J. and Reed, A. R., Permeability and air retention characteristics of bulk solid materials in relation to modes of dense-phase pneumatic conveyor performance, Bulk Solids Handling 7 (1987), Pages 415-425 